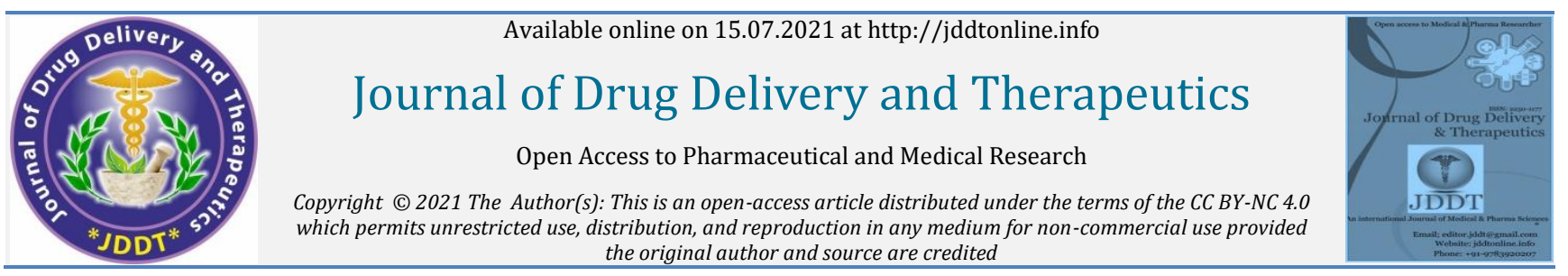

Copyright (C) 2021 The Author(s): This is an open-access article distributed under the terms of the CC BY-NC 4.0 the original author and source are credited

Review Article

Open Access Full Text Article

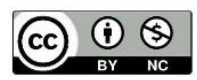

\title{
Integration of Complementary and Alternative Medicines in Health care system to combat COVID 19- A Validation
}

\author{
(1) Vaishali H. Shinde, Ramesh Bawaskar \\ Regional Research Institute for Homoeopathy, Mumbai, Under Central Council for Research in Homoeopathy, Ministry of AYUSH Govt. of India
}

\section{Article Info:}

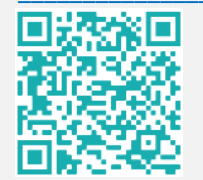

\section{Article History:}

Received 13 May 2021

Review Completed 22 June 2021

Accepted 28 June 2021

Available online 15 July 2021

*Address for Correspondence:

Vaishali H. Shinde, Research Officer (H.)/Scientist-3, Regional Research Institute for Homoeopathy, Mumbai Under Central Council for Research in Homoeopathy, Ministry of AYUSH Govt. of India. ORCID ID: https://orcid.org/0000-0001-8707-5942

\section{Cite this article as:}

Shinde VH, Bawaskar R, Integration of Complementary and Alternative Medicines in Health care system to combat COVID 19- A Validation, Journal of Drug Delivery and Therapeutics. 2021 11(4):96-100

DOI: http://dx.doi.org/10.22270/jddt.v11i4.4932

\section{Abstract}

Human mankind has always been under the wrath of various epidemics viz. Spanish Flu Asian Flu, Hong Kong Flu, influenza A-H1N1 virus, SARS in 2003, etc. The on-going COVID 19 pandemic has posed as a serious concern to humans with no proper treatment and no specific drugs against this virus. There have been various challenges to the current health care delivery system. There is dearth of reported RCTs evaluating effects of antivirals. Corticosteroid treatment has reported to have delayed coronavirus RNA clearance with its widespread use leading to development/exacerbation of fungal diseases like Mucormycosis. Various vaccines designed have many questions about their efficacy that may rise with time, as SARS-CoV-2 has numerous variants, and it can mutate over time. With limited success in developing antivirals, Complementary and Alternative medicines like Traditional Chinese medicines, Ayurvedic and homoeopathic medicines have been gaining momentums in recent years displaying promising results. Methodical researches are warranted to further evaluate the efficacy of Complementary and alternative medicines. For curtailing the devastating effects of COVID 19 requires reviewing the current health policies by integrating complementary medicine with conventional system. To channelize all the available therapeutic options to win the battle against COVID-19 is the need of hour.

Keywords: Ayurved, Complementary and alternative medicines, COVID-19, Homoeopathy SARS-CoV-2, Traditional Chinese medicines.

\section{INTRODUCTION}

With the discovery of tobacco mosaic virus in 1892 and footand-mouth disease virus in 1898 , the first to be discovered in humans was the yellow fever virus in $1901 .^{1}$ There are 219 virus species that are known to be able to infect humans. ${ }^{2}$ Human mankind has always been under the wrath of epidemics. Three influenza pandemics occurred during the 20th century, the most severe of which was the "Spanish Flu" in 1918-1919 caused by an A(H1N1) virus) with estimated 20-50 million deaths. In 1957-1958 the "Asian Flu" caused by an A (H2N2) virus and in 1968 the "Hong Kong Flu" caused by H3N2 virus with estimated 1-4 million deaths each. The first influenza pandemic of the 21st century in 2009-2010 was caused by an influenza A (H1N1) virus. ${ }^{3}$

In 2003, an outbreak of new infectious disease severe acute respiratory syndrome (SARS) caused tremendous social, political and economic disruptions in many countries across the world. From China the SARS virus spread to 30 countries. Due to the many questions remaining unanswered about SARS, World Health Organization (WHO) had warned that, "Continued global vigilance for SARS is crucial for the foreseeable future. The world is not yet SARS-free. SARS will continue to menace the global public health system. It is likely the virus still circulates in an animal reservoir and may cross into humans again when conditions are favourable". It was believed that SARS was a warning. ${ }^{4,5}$

Looking into the recent outbreaks of H1N1, hCoV, Hendra virus, Nipah virus, and MERS-CoV the Asia-Pacific region seems to be the global hot-spot for the emergence of novel RNA viruses. With human demographic history an estimation of 1 such event per 100 years is broadly consistent ${ }^{6}$

SARS-CoV-2 appeared in 2019 and rapidly spread to over 200 countries. With its rapid global spread re-emergence of the virus after alterations in its genome for stable adaptation is a serious concern to human health. It has a zoonotic origin from bats and animals to humans. With the sequencing and phylogenetic analysis done, it is found that this virus is novel with no cure for its infection. Its genome has similarities with those of SARS-CoV and MERS-CoV but due to mutations in the genome, it became a novel virus. It causes infections with mild symptoms viz. fever, flu, and cough to severe symptoms with clinical outcomes ARDS, septic shock, respiratory failure, and multi-organ dysfunction. With no specific drugs against this virus, and few vaccines been approved, preventive strategies still remain the mainstay. Diligent efforts are being done for identifying an effective treatment against the virus through various therapeutic targets which are involved in the host-virus interaction i.e., proteins, enzymes, pathways, and receptors. Various vaccines designed by using different techniques have been approved. 
The SARS-CoV-2 has several variants, and has potential to mutate in population over time. Therefore, many questions about the efficacy of vaccines may rise with time. Vaccines are approved for emergency use; however, they have not been fully evaluated for efficacy against SARS-CoV-2 variants that recently emerged in the UK, South Africa and India. ${ }^{7}$

\section{CHALLENGES TO EXISTING HEALTH CARE SYSTEM}

COVID-19 has been an ongoing pandemic with no curative treatment. Treatment of hospitalized patients with symptomatic COVID comprises of supportive care, including oxygenation, mechanical ventilation, hemodynamic support with management of co-morbidities and complications. Various therapies have been proposed for the treatment and are currently being used but are further being tested for their safety and effectiveness. With no specific drugs available for COVID-19 to date different combinations of medicines and therapies are being used to treat patients. Antiviral and anti-inflammatory treatments have been utilized. ${ }^{7}$

Though evidence of favipiravir in COVID-19 shows its usefulness in the management of mild to moderate COVID19; however whether its effect translates to clinical benefits like shortening the disease course, early hospital discharge, and reducing the oxygen requirement prerequisites large randomized controlled trials. ${ }^{8}$

Despite showing strong antiviral effects in preclinical models of infection with coronaviruses intravenous remdesivir was not found to significantly improve the time to clinical improvement, mortality, or time to virus clearance compared with placebo. Remdesivir did not result in significant reductions in SARS-CoV-2 RNA loads or detectability in upper respiratory tract or sputum specimens. Rather a higher proportion of remdesivir recipients than placebo recipients had to prematurely stop dosing due of adverse events including gastrointestinal symptoms (anorexia, nausea, and vomiting), aminotransferase or bilirubin increases, and worsened cardiopulmonary status. Intravenous remdesivir did not produce substantial clinical and antiviral effects in critical patients with COVID-19.9

RCTs evaluating effects of remdesivir in hospitalized COVID19 patients are deficit. Important questions remains unclear regarding the efficacy of remdesivir viz. the optimal duration of therapy, effect on discrete clinical outcomes, the relative effect of the drug if given in the presence of dexamethasone or other corticosteroids. Until stronger evidence emerges, it cannot be concluded that remdesivir is efficacious for treating COVID-19.10,11

Corticosteroid therapy was commonly used among critically ill patients with Middle East Respiratory Syndrome (MERS), but its impact on outcomes was uncertain. Corticosteroid therapy in patients with MERS was not associated with a difference in mortality but was associated with delayed MERS coronavirus RNA clearance. 12

The outcome of corticosteroid on the viral load of Severe Acute Respiratory Syndrome (SARS) patients is unidentified. A higher plasma viral load is associated with early corticosteroid treatment.$^{13}$

COVID-19 due to its immune dysregulation is associated with a significant incidence of secondary infections, both bacterial and fungal probably. Additionally, the widespread use of steroids/monoclonal antibodies/broad-spectrum antibiotics against COVID-19 may have lead to the development/ exacerbation of fungal diseases. ${ }^{14}$ Uncontrolled diabetes and over-zealous use of steroids are aggravating the illness with new manifestations appearing over time like the mucormycosis. ${ }^{15}$

It is not clear whether a vaccine will confer long-term immunity like measles or short-term immunity as with flu. Unless a vaccine is given to all eight billion inhabitants of the world who are not currently sick or recovered, COVID-19 is likely to become endemic ${ }^{16}$.

The coronavirus data from Seychelles reported more than a third of people who tested positive for COVID-19 had been fully vaccinated. Some $37 \%$ of those testing positive had received both doses of a vaccine. The WHO said vaccination alone would not stop transmission entirely, and preventive health measures such as social distancing, mask-wearing and hand washing has to continue. ${ }^{17}$

The coronavirus, like most viruses, will live on. Estimates about the culmination of COVID-19 pandemic are speculative, but it will most likely involve a blend of factors that mediated in the past pandemics ${ }^{16}$.

In controlling 2003 SARS pandemic twenty-first century science played a relatively small role; nineteenth-century techniques continued to prove their value. ${ }^{4}$ There are good reasons for us to learn from ancient wisdom and accumulated clinical experience, in combination with cutting edge science and technologies, to fight with the devastating COVID-19 pandemic now and emerging new viruses in the future.

\section{COMPLEMENTARY MEDICINE AN OPTION TO COUNTER COVID 19}

The integration of traditional and modern medicine may offer valuable experience and can contribute for an allaround progress in human medicine is as evident from the ongoing global fight against COVID-19.18 In the treatment of viral infections natural products and their derivatives have shown potential activities. 19,20

In the inhibition and treatment of respiratory diseases Traditional Chinese Medicine (TCM) has suggested clinical experiences, effective and applicable herbal formulas 21 When COVID-19 wrecked in Wuhan, China patients admitted to the TCM Hospital were immediately treated with TCM and reported with $>90 \%$ efficacy. TCM was based on the TCM theory of restoring the human immune system, thus conquering the viral infection indirectly. ${ }^{22}$ A range of Chinese herbal medicines have been documented to have very promising anti-SARS-CoV-2 agents having potential activity against SARS-CoV-2 and have attracted significant attention due to their activities both in vitro and in clinical practice. ${ }^{23}$ Some studies showed that Chinese herbal formula may be associated with blocking of the viral proliferation 24

During the Severe Acute Respiratory Syndrome (SARS) epidemic TCM was effective. It was reported that about $85 \%$ of COVID-19 patients received combined treatment with TCM and regular medication. Positive outcomes of TCM treatment have been reported. In research laboratory settings antiviral and immune modulation properties have been shown by herbs and their phytoactive components with serious consideration been given to further rigorous scientific studies even outside of China. The potential contribution of TCM to health and well-being has been highlighted in the WHO global report on Traditional and Complementary Medicine.25, 26, 27, 28, 29 Chinese medicinal herbs could be an alternative strategy for the prevention of COVID-19 in high-risk populations. ${ }^{30}$ TCM is mentioned to be the best choice for the treatment and prevention and is expected to be promoted. ${ }^{31}$ 
Presently, there is good evidence that it has role in affecting the transcription, replication, binding of SARS-CoV-2 and tempering the cytokine storm. TCM can effectively alleviate the symptoms of suspected and confirmed COVID-19 by delaying the progression of disease thereby reducing the mortality. ${ }^{32}$ Though combination of western medicine and TCM in treatment were documented of great significance for the prevention and treatment of COVID-19 further relevant laboratory research and clinical evaluation is needed to collect scientific evidences on its efficacy. ${ }^{33}$

For the treatment of several diseases Indian medicinal plants have been a promising field 34 . Ayurveda and Siddha practices originated in India and are still commonly used among the Indian population. In addition, identification of phyto-components of medicinal plants may be helpful. Therefore, Indian medicinal plants can be deliberated as an added option for their role to combat viral infections 35 .

There are reports of beneficial outcomes of Ayurvedic interventions in hypoxia that seems to have the potential to supplement standard of care for COVID-19. Ayurvedic intervention in early stages of decreasing peripheral oxygen saturation could possibly prevent the need for oxygen supplementation and hospitalization. To explore the option of incorporating the Ayurvedic treatment with standard care rigorous clinical studies need to be undertaken 36

The role of Homeopathic medicines have been reportedly documented for the prevention of Cholera, Spanish Influenza, Yellow fever, Scarlet fever, Diphtheria, Typhoid, etc. ${ }^{37}$ The homoeopathic intervention has played a considerable role in managing Spanish Flu 1918 pandemic not only by treating but also by reducing the mortality ${ }^{38}$. Usefulness of homoeopathic medicine Bryonia alba 30C as Genus Epidemicus for the prevention of chikungunya is also documented ${ }^{39}$. Studies have also shown that homeopathy may be an effective adjunct in Dengue outbreak prevention. ${ }^{40,41}$ In the 2009 pandemic of A/H1N1 influenza, contribution with regard to influenza-like illness has also been done. 42,43

Catalonia, Spain reported positive outcomes of homoeopathic treatment in mild and moderate cases of COVID 1944. Various studies are being undertaken in different settings in India, a few aimed at prophylaxis and others aimed at treatment the outcomes of which might provide evidence for clinically repurposing homeopathy's medicines in COVID-19 as an adjuvant or stand-alone 45

Homoeopathic medicines cause immune modulating changes through various mechanisms and thus are suggestive of being useful in boosting the immunological responses in various conditions ${ }^{46}$ so possibly will prove as an excellent alternative in COVID 19 treatment.

\section{THE RATIONALE FOR INTEGRATION OF COMPLEMENTARY MEDICINE}

Although biomedical knowledge has made a noteworthy progress, there has been recurrent emergence and reemergence of deadly viral infections widely affecting human health. Though with a large mammalian viruses being identified, there are large numbers of evolving viruses in the offing to adapt and infect ${ }^{47}$. It seems predictable that new viruses will continue to emerge. The emergence of new viruses is a long-standing and continuing biological progression. It is unclear whether this process will eventually slow down or stop or whether it will continue indefinitely if a significant proportion of newly discovered virus species are newly evolved. If anthropogenic drivers of this process are important then it is possible that we are in the midst of a period of particularly rapid virus emergence ${ }^{48}$.

The unavoidable conclusion is that we must anticipate the emergence and/or discovery of more new human viruses in the coming years and decades. ${ }^{48}$ By no means all of these will pose a serious risk to public health but, if the recent past is a reliable guide to the immediate future, it is very likely that some will.48

With the unpredictable nature of novel infections, there is a further need for devoted research to understand the new viral pathogens and human susceptibilities and to develop counter-measures. ${ }^{47}$

With limited success in developing broad spectrum antivirals especially for RNA viruses, herbal medicines used in traditional Chinese or Indian system of medicine are generally considered "safe" due to their widespread use over centuries. Though assessing efficacy of traditional herbal remedies are often difficult due to inadequate, inconsistent methods being used across studies and lack of similar rigor like other medical research in researches involving herbal remedies. Randomized clinical trials involving herbal remedies conducted with sound and consistent methodology are the necessity of this hour. ${ }^{49}$

With no robust evidence for effective prevention and specific therapy at the global level to combat this COVID-19 pandemic , Complementary and Integrative Medicine (CIM) holds a substantial potential for building resilience using herbs and so it should be subjected to further scientific attention and clinical research. From substantial preclinical and limited clinical research it's known that many botanicals have properties that protect against respiratory viruses.

CIM offers a variety of easily feasible, accessible, evidencebased preventive and therapeutic options for respiratory infections and for strengthening physical and mental resilience, likely to also help in prevention and treatment of COVID-19. Although the literature on CIM topics is gradually increasing, high-quality evidence is still lacking. Particularly, further clinical research is needed, including methodologically high-quality studies. All this would require a national and national initiative to facilitate the necessary substantial research to define possible contributions of CIM in the COVID-19 pandemic and beyond. ${ }^{50}$

In addition, preclinical and clinical trial evaluations of CIM for COVID-19 have not specifically been conducted, so further investigations related to this are warranted.51 Although, traditional Chinese herbal medicine in used for COVID-19 pneumonia, its efficacy remains uncertain. 52

In a bibliometric analysis of global research trends at the intersection of COVID-19 and Traditional, integrative, complementary and alternative medicines (TICAMs) findings include the fact that a wide-range of TICAMs have been mentioned across articles; a total of 327 TICAMs were mentioned across the 296 eligible articles with the vast majority of them including traditional Chinese medicine. Eligible articles were published by authors with affiliations in 56 countries, the most common of which included China, the United States, India and Italy. 53

Chinese, Indian and Iranian herbal medicine with 1000 years' experience in the prevention of pandemic and endemic infectious diseases are providing as an alternative contender for controlling COVID-19 infection. This is the biggest opportunity to test complementary medicines. Hopefully, positive results from clinical trial experiments explicate the positive effects of Chinese, Indian and Iranian herbal medicine alone and as adjuvant to recovery of SARS- 
CoV-2 with further studies needed to discover the novel antiCOVID-19 substances. ${ }^{54}$

India has a pluralistic system for health care delivery wherein along with the conventional medicine coexists the traditional systems of medicine such as Ayurveda, yoga and naturopathy, Unani, Siddha, Sowa Rigpa, and homoeopathy (AYUSH) which functions under the Ministry of AYUSH (MoA). Findings have asserted that during the COVID-19 pandemic a large proportion of the population practiced AYUSH measures across the country and have benefitted considerably. 55

WHO is working with some research institutions around the world to select traditional medicine products with potential use for the treatment of COVID-19 after being investigated for clinical efficacy and safety. The WHO has been working with countries to ensure the safest and most effective use of traditional medicines, and it will continue to give support in exploring the benefits of traditional medicines. Traditional medicines need to be robustly investigated to avoid putting the lives of people in danger during the period of this pandemic and beyond 56

Improving the situation will require both political will and considerable investment in infrastructure, human capacity and new tools. ${ }^{57}$ It needs social and political determination to channelize all the available therapeutic options to win the battle against COVID-19.

\section{CONCLUSION}

COVID 19 pandemic has placed the most advanced public health systems into crisis. Countering the ongoing pandemic requires restoring, strengthening and reviewing the current health policies. With the Complementary and alternative medicines gaining momentum in recent years the current health policies are to be revised by integrating complementary medicine with conventional system for curtailing the devastating effects the pandemic worldwide. Bigotry or ignorance cannot be valid reasons to rule out Complementary and alternative medicines as an adjuvant tool in the fight against resurgent epidemics/pandemics. Methodical researches are warranted to further evaluate the efficacy of Complementary and alternative medicines

\section{REFERENCES}

1. Fields, Bernard N, David M. Knipe, and Peter M. Howley. Fields Virology. Philadelphia: Wolters Kluwer Health/Lippincott Williams \& Wilkins, 2007. Print.

2. Woolhouse M, Scott F, Hudson Z, Howey R, Chase-Topping M. Human viruses: discovery and emergence. Philos Trans R Soc Lond B Biol Sci. 2012 Oct 19; 367(1604):2864-71. PMID: 22966141; PMCID: PMC3427559. https://doi.org/10.1098/rstb.2011.0354

3. World Health Organization/Europe. Past pandemics. [Internet]. Europe. WHO/Europe. [cited on 10.05.2021]. Available from: https://www.euro.who.int/en/health-topics/communicablediseases/influenza/publications.

4. Chew SK. SARS: how a global epidemic was stopped. Bull World Health Organ. 2007; 85(4):324. https://doi.org/10.2471/BLT.07.032763

5. World Health Organization. SARS outbreak contained worldwide. [Internet]. Geneva. WHO. [Updated on 2003 July 5; cited on 10.05.2021]. Available from: https://www.who.int/mediacentre/news/releases/2003/pr56/en/

6. Wolfe, N., Dunavan, C. \& Diamond, J. Origins of major human infectious diseases. Nature 447, 279-283 (2007). https://doi.org/10.1038/nature05775

7. Mehmood I, Ijaz M, Ahmad S, Ahmed T, Bari A, Abro A, Allemailem KS, Almatroudi A, Tahir Ul Qamar M. SARS-CoV-2: An Update on Genomics, Risk Assessment, Potential Therapeutics and Vaccine Development. Int J Environ Res Public Health. 2021 Feb 8;
18(4):1626. PMCID: PMC7915969.

https://doi.org/10.3390/ijerph18041626

8. Joshi S, Parkar J, Ansari A, Vora A, Talwar D, Tiwaskar M, Patil S, Barkate H. Role of favipiravir in the treatment of COVID-19. Int J Infect Dis. 2021 Jan; 102:501-508. Epub 2020 Oct 30. PMID: 33130203; PMCID: PMC7831863. https://doi.org/10.1016/j.ijid.2020.10.069

9. Wang Y, Zhang D, Du G, Du R, Zhao J, Jin Y, et al. Remdesivir in adults with severe COVID-19: a randomised, double-blind, placebocontrolled, multicentre trial. Lancet. 2020 May 16; 395(10236):1569-1578. doi: 10.1016/S0140-6736(20)31022-9. Epub 2020 Apr 29. Erratum in: Lancet. 2020 May 30; 395(10238):1694. PMID: 32423584; PMCID: PMC7190303.

10. Piscoya A, Ng-Sueng LF, Parra Del Riego A, Cerna-Viacava R, Pasupuleti V, Roman YM, Thota P, White CM, Hernandez AV. Efficacy and harms of remdesivir for the treatment of COVID-19: A systematic review and meta-analysis. PLoS One. 2020 Dec 10; 15(12):e0243705 PMCID: PMC7728272.

https://doi.org/10.1371/journal.pone.0243705

11. McCreary EK, Angus DC. Efficacy of Remdesivir in COVID-19. JAMA. 2020; 324(11):1041-1042. https://doi.org/10.1001/jama.2020.16337

12. Arabi YM, Mandourah Y, Al-Hameed F, Sindi AA, Almekhlafi GA, Hussein MA, et al. Corticosteroid Therapy for Critically Ill Patients with Middle East Respiratory Syndrome. Am J Respir Crit Care Med. 2018 Mar 15; 197(6):757-767. PMID: 29161116 https://doi.org/10.1164/rccm.201706-11720C

13. Lee N, Allen Chan KC, Hui DS, Ng EK, Wu A, Chiu RW, Wong VW, Chan PK, Wong KT, Wong E, Cockram CS, Tam JS, Sung JJ, Lo YM. Effects of early corticosteroid treatment on plasma SARS-associated Coronavirus RNA concentrations in adult patients. J Clin Virol. 2004 Dec; 31(4):304-9. PMID: 15494274; PMCID: PMC7108318. https://doi.org/10.1016/j.jcv.2004.07.006

14. Mehta S, Pandey A. Rhino-Orbital Mucormycosis Associated With COVID-19. Cureus. 2020 Sep 30; 12(9):e10726. PMCID PMC7599039. https://doi.org/10.7759/cureus.10726

15. Sharma S, Grover M, Bhargava S, Samdani S, Kataria T. Post coronavirus disease mucormycosis: a deadly addition to the pandemic spectrum [published online ahead of print, $2021 \mathrm{Apr} 8$ ]. J Laryngol Otol. 2021; 1-6. https://doi.org/10.1017/S0022215121000992

16. Denworth L. How the COVID-19 Pandemic Could End. What Comes Next. 2020; 322(6):44-45. Available from: https://www.scientificamerican.com/article/how-the-covid-19pandemic-could-end1/.

17. Reuters Staff. WHO Reviewing Seychelles COVID-19 Data After Fully Vaccinated People Test Positive. Reuters. [Nairobi]. May 12, 2021. Available from: https://www.medscape.com/viewarticle/950898.

18. Ni L, Chen L, Huang X, et al. Combating COVID-19 with integrated traditional Chinese and Western medicine in China. Acta Pharm Sin B. 2020; 10(7):1149-1162. https://doi.org/10.1016/j.apsb.2020.06.009

19. Denaro M, Smeriglio A, Barreca D, De Francesco C, Occhiuto C, Milano G, Trombetta D. Antiviral activity of plants and their isolated bioactive compounds: An update. Phytother Res. $2020 \mathrm{Apr}$; 34(4):742-768. PMID: 31858645. https://doi.org/10.1002/ptr.6575

20. Oyero OG, Toyama M, Mitsuhiro N, Onifade AA, Hidaka A, Okamoto M, Baba M. SELECTIVE INHIBITION OF HEPATITIS C VIRUS REPLICATION BY ALPHA-ZAM, A NIGELLA SATIVA SEED FORMULATION. Afr J Tradit Complement Altern Med. 2016 Sep 29, 13(6):144-148. PMID: 28480371; PMCID: PMC5412185. https://doi.org/10.21010/ajtcam.v13i6.20

21. Cui H.-T., Li Y.-T., Guo L.-Y., Liu X.-G., Wang L.-S., et al. Traditional Chinese medicine for treatment of coronavirus disease 2019: a review. Tradit. Med. Res. 2020; 5(2):65-73. https://doi.org/10.53388/TMR20200222165

22. Lee DYW, Li QY, Liu J, Efferth T. Traditional Chinese herbal medicine at the forefront battle against COVID-19: Clinical experience and scientific basis. Phytomedicine. 2021 Jan; 80:153337. Epub 2020 Sep 28. PMID: 33221457; PMCID: PMC7521884. https://doi.org/10.1016/j.phymed.2020.153337

23. Wang Z, Yang L. Chinese herbal medicine: Fighting SARS-CoV-2 infection on all fronts. J Ethnopharmacol. 2021 Apr 24; 270:113869. 
\Epub 2021 Jan 21. PMID: 33485973; PMCID: PMC7825841. https://doi.org/10.1016/j.jep.2021.113869

24. Tong X, Li A, Zhang Z, Duan J, Chen X, Hua C, Zhao D, Xu Y, Shi X, Li P, Tian X, Lin F, Cao Y, Jin L, Chang M, Wang Y. TCM treatment of infectious atypical pneumonia--a report of 16 cases. J Tradit Chin Med. 2004 Dec; 24(4):266-9. PMID: 15688692

25. Capodice, J.L., Chubak, B.M. Traditional Chinese herbal medicinepotential therapeutic application for the treatment of COVID-19. Chin Med 2021; 16:24. https://doi.org/10.1186/s13020-020-00419-6

26. Ling CQ. Traditional Chinese medicine is a resource for drug discovery against 2019 novel coronavirus (SARS-CoV-2). J Integr Med. 2020; 18(2):87-8. [PubMed: 32122812]. [PubMed Central: PMC7129043]. https://doi.org/10.1016/j.joim.2020.02.004

27. Yang Y, Islam MS, Wang J, Li Y, Chen X. Traditional Chinese Medicine in the Treatment of Patients Infected with 2019-New Coronavirus (SARS-CoV-2): A Review and Perspective. Int J Biol Sci. 2020; 16(10):1708- 17. [PubMed: 32226288]. [PubMed Central: PMC7098036]. https://doi.org/10.7150/ijbs.45538

28. Luo E, Zhang D, Luo H, Liu B, Zhao K, Zhao Y, et al. Treatment efficacy analysis of traditional Chinese medicine for novel coronavirus pneumonia (COVID-19): an empirical study from Wuhan, Hube Province, China. Chin Med. 2020; 15:34. [PubMed: 32308732]. [PubMed Central: PMC7156896]. https://doi.org/10.1186/s13020020-00317-x

29. COVID-19 Pandemic: The Role of Traditional Medicine Faisal Muhammad 1, Int J Infect. 2020 July; 7(3):e107090 https://doi.org/10.5812/iji.107090

30. Zumla A., Chan J.F., Azhar E.I., Hui D.S., Yuen K.-Y. Coronaviruses-drug discovery and therapeutic options. Nat. Rev. Drug Discov. 2016; 15(5):327. https://doi.org/10.1038/nrd.2015.37

31. Zhao Z, Li Y, Zhou L, et al. Prevention and treatment of COVID-19 using Traditional Chinese Medicine: A review. Phytomedicine. 2021; 85:153308. https://doi.org/10.1016/j.phymed.2020.153308

32. An X, Zhang Y, Duan L, Jin D, Zhao S, Zhou R, Duan Y, Lian F, Tong X. The direct evidence and mechanism of traditional Chinese medicine treatment of COVID-19. Biomed Pharmacother. 2021 May; 137:111267. Epub 2021 Jan 14. PMID: 33508618; PMCID: PMC7836975. https://doi.org/10.1016/j.biopha.2021.111267

33. Wu XV, Dong Y, Chi Y, Yu M, Wang W. Traditional Chinese Medicine as a complementary therapy in combat with COVID-19-A review of evidence-based research and clinical practice. J Adv Nurs. 2021 Apr; 77(4):1635-1644. Epub 2020 Nov 29. PMID: 33174654. https://doi.org/10.1111/jan.14673

34. Vellingiri B, Jayaramayya K, Iyer M, et al. COVID-19: A promising cure for the global panic. Sci Total Environ. 2020; 725:138277. https://doi.org/10.1016/j.scitotenv.2020.138277

35. Balachandar V., Mahalaxmi I., Kaavya J., Vivekanandhan G, Ajithkumar S., Arul N, et al. COVID-19: emerging protective measures. Eur. Rev. Med. Pharmacol. Sci. 2020; 24(6):3422-3425.

36. Joshi J, Puthiyedath R. Outcomes of Ayurvedic care in a COVID-19 patient with hypoxia - A case report. Journal of Ayurveda and Integrative Medicine. 2020.

https://doi.org/10.1016/j.jaim.2020.10.006

37. Jacobs J. Homeopathic prevention and management of epidemic diseases. Homeopathy 2018; 107:157-60. https://doi.org/10.1055/s-0038-1649487

38. Shinde VH. Homoeopathy in pandemic Spanish flu 1918. Indian J Res Homoeopathy 2020;14:152-9.

https://doi.org/10.4103/ijrh.ijrh_32_20

39. Nayak, Debadatta. Homoeopathic Genus Epidemicus 'Bryonia alba' as a prophylactic during an outbreak of Chikungunya in India: A cluster -randomised, double -blind, placebo- controlled trial. Indian Journal of Research in Homoeopathy. 2014; 8:160-165. https://doi.org/10.4103/0974-7168.141739

40. de Souza Nunes LA. Contribution of homeopathy to the control of an outbreak of dengue in Macaé, Rio de Janeiro. Int J High Dilution Res 2008; 7:186-92.
41. Bawaskar RS, Shinde VH. A Review of homoeopathic research in the prevention and treatment of dengue fever. Homoeopathic Links 2019; 32:10-7. https://doi.org/10.1055/s-0039-1687897

42. Mathie RT, Baitson ES, Frye J, Nayak C, Manchanda RK, Fisher P. Homeopathic treatment of patients with influenza like illness during the 2009 A/H1N1 influenza pandemic in India. Homeopathy 2013; 102:187-92. https://doi.org/10.1016/j.homp.2013.04.001

43. Vincent S, Demonceaux A, Deswarte D, Scimeca D, Bordet MF. Management of influenza like illness by homeopathic and allopathic general practitioners in France during the 2009-2010 influenza season. J Altern Complement Med 2013; 19:146-52. https://doi.org/10.1089/acm.2011.0706

44. Clapers M, Velat M, Clapers J, Vidal-Jové J, Mora J. Analysis of Homeopathic Genus Epidemicus for COVID-19 Patients in Spain. Homeopathy. Publication Date: 25 May 2021 (online)

45. Varanasi R, Nayak D, Khurana A. Clinical Repurposing of Medicines is Intrinsic to Homeopathy: Research Initiatives on COVID-19 in India Homeopathy. 2021 Apr 14. Epub ahead of print. PMID: 33853178. https://doi.org/10.1055/s-0041-1725988

46. Vaishali Shinde, Ramesh Bawaskar. Homoeopathy and ImmunologyA Narrative Review. Indo Am.J.P.Sci, 2021; 08(06).

47. Parvez M.K, Parveen S. Review Evolution and Emergence of Pathogenic Viruses: Past, Present, and Future Intervirology 2017; 60:1-7 https://doi.org/10.1159/000478729

48. Woolhouse M, Scott F, Hudson Z, Howey R, Chase-Topping M. Human viruses: discovery and emergence Philos Trans R Soc Lond B Biol Sci. 2012 Oct 19; 367(1604):2864-2871. https://doi.org/10.1098/rstb.2011.0354

49. Ganguly S, Bakhshi S. Traditional and complementary medicine during COVID 19 pandemic Phytother Res. 2020 Aug 12: https://doi.org/10.1002/ptr.6828

50. Seifert G, Jeitler M, Stange R, Michalsen A, Cramer H, Brinkhaus B, et al. The Relevance of Complementary and Integrative Medicine in the COVID-19 Pandemic: A Qualitative Review of the Literature. Front Med (Lausanne). 2020 Dec 11; 7:587749. PMID: 33363186; PMCID: PMC7761649. https://doi.org/10.3389/fmed.2020.587749

51. Nugraha RV, Ridwansyah H, Ghozali M, Khairani AF, Atik N. Traditional Herbal Medicine Candidates as Complementary Treatments for COVID-19: A Review of Their Mechanisms, Pros and Cons. Evid Based Complement Alternat Med. 2020 Oct 10;2020:2560645. PMID: 33101440; PMCID: PMC7569437. https://doi.org/10.1155/2020/2560645

52. Zhang MM, Liu XM, He L. Effect of integrated traditional Chinese and Western medicine on SARS: a review of clinical evidence. World J Gastroenterol. 2004; 10(23):3500-3505 https://doi.org/10.3748/wjg.v10.i23.3500

53. Jeremy Y. Ng. Global research trends at the intersection of coronavirus disease 2019 (COVID-19) and traditional, integrative, and complementary and alternative medicine: a bibliometric analysis. BMC Complement Med Ther 2020; 20:353. https://doi.org/10.1186/s12906-020-03151-8

54. Mirzaie A, Halaji M, Dehkordi FS, Ranjbar R, Noorbazargan H. A narrative literature review on traditional medicine options for treatment of corona virus disease 2019 (COVID-19). Complement Ther Clin Pract. 2020 Aug; 40:101214. Epub 2020 Jun 17. PMID: $32891290 ;$ PMCID: PMC7831809. https://doi.org/10.1016/j.ctcp.2020.101214

55. Srikanth N, Rana R, Singhal R, Jameela S, Singh R, Khanduri S, et al. Mobile App-Reported Use of Traditional Medicine for Maintenance of Health in India During the COVID-19 Pandemic: Cross-sectional Questionnaire Study. JMIRx Med. 2021 May 7; 2(2):e25703. PMID 34032815; PMCID: PMC8110045. https://doi.org/10.2196/25703

56. World Health Organization. WHO supports scientifically-proven traditional medicine. 2020, [cited May 28, 2020]. Available from: https://www.afro.who.int/news/who-supports-scientificallyproventraditional-medicine.

57. King DA, Peckham C, Waage JK, Brownlie J, Woolhouse ME Epidemiology. Infectious diseases: preparing for the future. Science. 2006 Sep 8; 313(5792):1392-3. https://doi.org/10.1126/science.1129134 